\title{
FAVORING AND DISFAVORING FACTORS FOR CULTURAL TOURISM EXPLOITING OF HISTORICAL MONUMENTS IN TRANSYLVANIA, ROMANIA
}

DOI: http://dx.doi.org/10.18509/GBP.2019.49

UDC: 338.48-6:7/8(498.4)

\author{
Roxana-Andreea Radu ${ }^{1}$ \\ Camelia Teodorescu ${ }^{1}$ \\ Ana-Maria Ciobotaru' ${ }^{1}$ \\ Iulia Daniela Nedelcu ${ }^{1}$ \\ Razvan Catalin Dobrea ${ }^{2}$ \\ ${ }^{1}$ Faculty of Geography, CAIMT (Research Center for Integrated Analysis and Territorial \\ Management), University of Bucharest, Romania \\ ${ }^{2}$ Bucharest Academy of Economic Studies, Department of Management, Romania
}

\begin{abstract}
Each historical province of Romania has a significant number of monuments, the cultural value of which can be used to create opportunities for tourism development of some geographical areas or localities. The study seeks to identify these monuments, capable of meeting the requirements imposed by the cultural-tourist activity through: accessibility, originality, seniority, maintenance or level of rehabilitation and promotion. The geographically analyzed area is the historical and geographical province of Transylvania, Romania. It is a province with a great historical load, and the presence of monuments has a rather high density. The steps taken to carry out this study followed, first of all, the crossing of the List of Cultural Monuments issued by the Ministry of Culture of Romania. The second stage is the individual analysis on the field of each monument mentioned in the list, as well as the identification of the appropriate level of cultural and tourist valorization, according to the mentioned criteria. The results of the study show, first of all, a difference between the large number of existing cultural monuments and the value of which is undoubtedly quite high by what they represent historically, and the smaller number of monuments that can be valorized from the cultural and tourism point of view. The requirements of the tourists and, generally, of the tourist activity, do not allow the entry and usage of the monuments that have very low levels of accessibility, originality or rehabilitation within touristic circuits or tourist offerings.
\end{abstract}

Keywords: cultural tourism, restrictivity, historical monuments, Transylvania, tourist offer

\section{INTRODUCTION}

The attraction for cultural tourism and for the discovery of cultural values at a certain historical stage, represented in particular by historical monuments, has existed and continues to be an important form of attraction for all generations.

The scrutiny of the historical stages of each geographical area leaves as proof of existence and evolution, monuments that attest having belonged to periods of economic growth, cultural influence, domination of a political regime or having belonged to a religious cult. Thus, one of the historical provinces in Romania where these monuments are well represented, is Transylvania. The history of this province is well depicted in all phases, 
starting with the ancient period, with monuments attesting the presence of the Dacians, and up to the Dacian - Roman wars with monuments raised by the Romans. The medieval period is well represented by the numerous monuments built in here, both by the local population, as well as with the influences given by the political regime that is dominant within this Romanian geographic space (the Habsburg Empire). The modern period adds value to the number and typology of monuments, presenting itself today as a blend, the cultural importance of which must be recognized [9].

The research done so far has shown that Transylvania is a historical province with a great cultural load, determined by a tumultuous history. Here, cultural tourism acquires special significance, obliging us to preserve and give it the right value [2], [1], [7].

The overall picture can be obtained by thorough research into the historical monuments that are specific to each historical period. This is the proposed methodology, starting from the Lists of Historical Monuments, issued by the Ministry of Culture in Romania. Between simply enumerating the discovered monuments into a complete list, and the real possibility of viewing them on the ground and of accessing the information by those interested, there is a big difference [3], [5]. The study is based on the differentiated analysis of these two things, thus offering the opportunity to the people interested in the values of the Romanian culture in Transylvania, to access them correctly [6], [10], [11]. Between the tourist activity and the presence of monuments and the cultural life involved, there is a link of reciprocity: either one can help the other prosper [4, [1], [8].

\section{MATERIALS AND METHODS}

There is a quite close relationship between the location of historical monuments and the type of relief. The hydrographic network has played a particularly important role here, with an impressive number of monuments found along the banks of the river, which can only testify once more to the existence of the population and culture in these areas. Transylvania, through its position in the central area of Romania (figure 1), provides these conditions, besides the already mentioned historical ones.

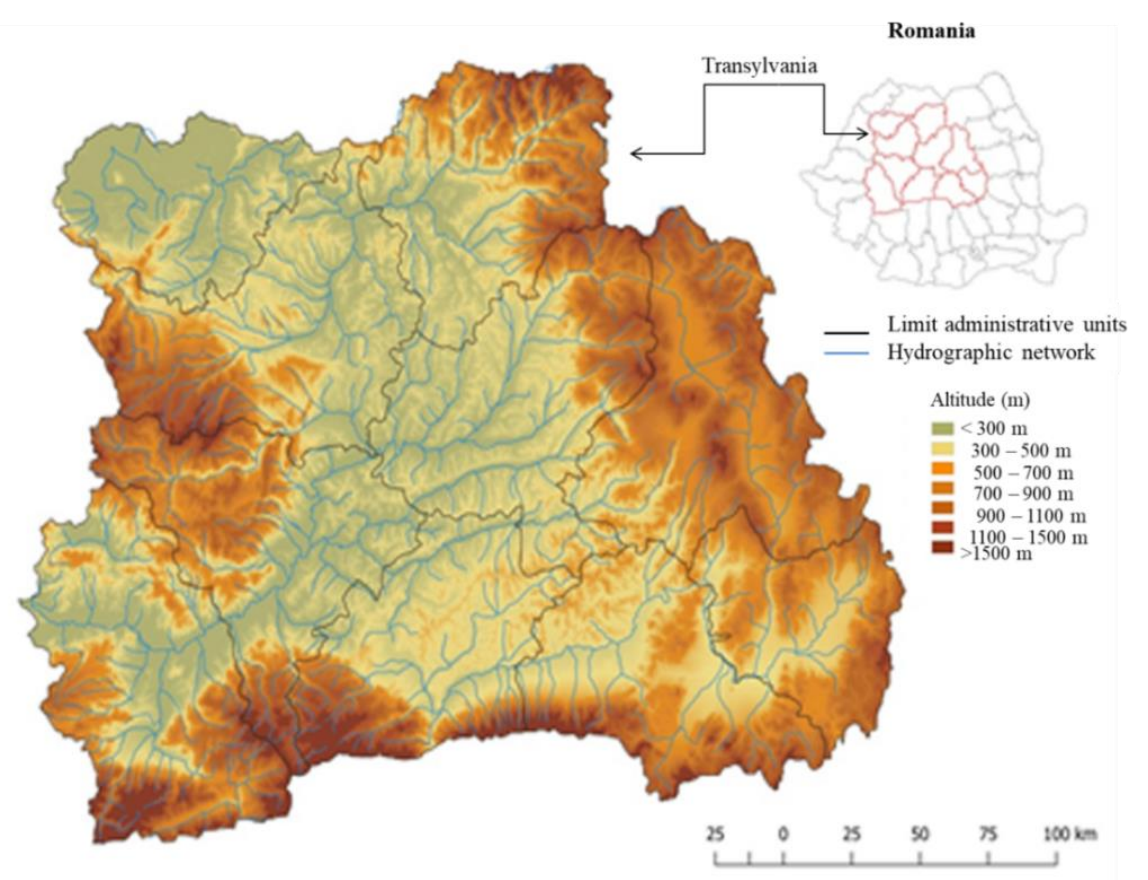

Figure 1. Localisation of the research area - Transilvania, Romania 


\section{RESULTS AND DISCUSSIONS}

Lying at the heart of the present research, there has been the List of Historical Monuments dating back of 2015, as issued by the Ministry of Culture and National Heritage in the Official Journal of Romania. From this data, information about the monuments existing in the Transylvanian region has been extracted, grouped by category, year or century and class. The next step was to create the graphic materials, this way: using the QGIS software, maps have been made for each category of monuments, dating back of each century, in order to determine which century most of the historical monuments belonged to. In addition to the data extracted from the Monuments List, mapping required geospatial data; as well as vector and raster data, such as the boundaries of counties and administrative units, geographic relief units, access routes and hydrographic network (Figure 2).

Field research has revealed a number of differences from what the Monuments List provides. Many of the monuments mentioned in the list are dated, but the accessibility, presentation quality, degree of wear or physical condition, as well as their rehabilitation, simply do not allow them to be valorised in terms of tourism. Another problem is property issue. Some of these monuments are located on a private property where access is limited or prohibited. It is precisely for these reasons that, we consider that only the ones worthy to visit should appear in another graphic representation that could support cultural tourism or cultural tourism consumers (Figure 3).

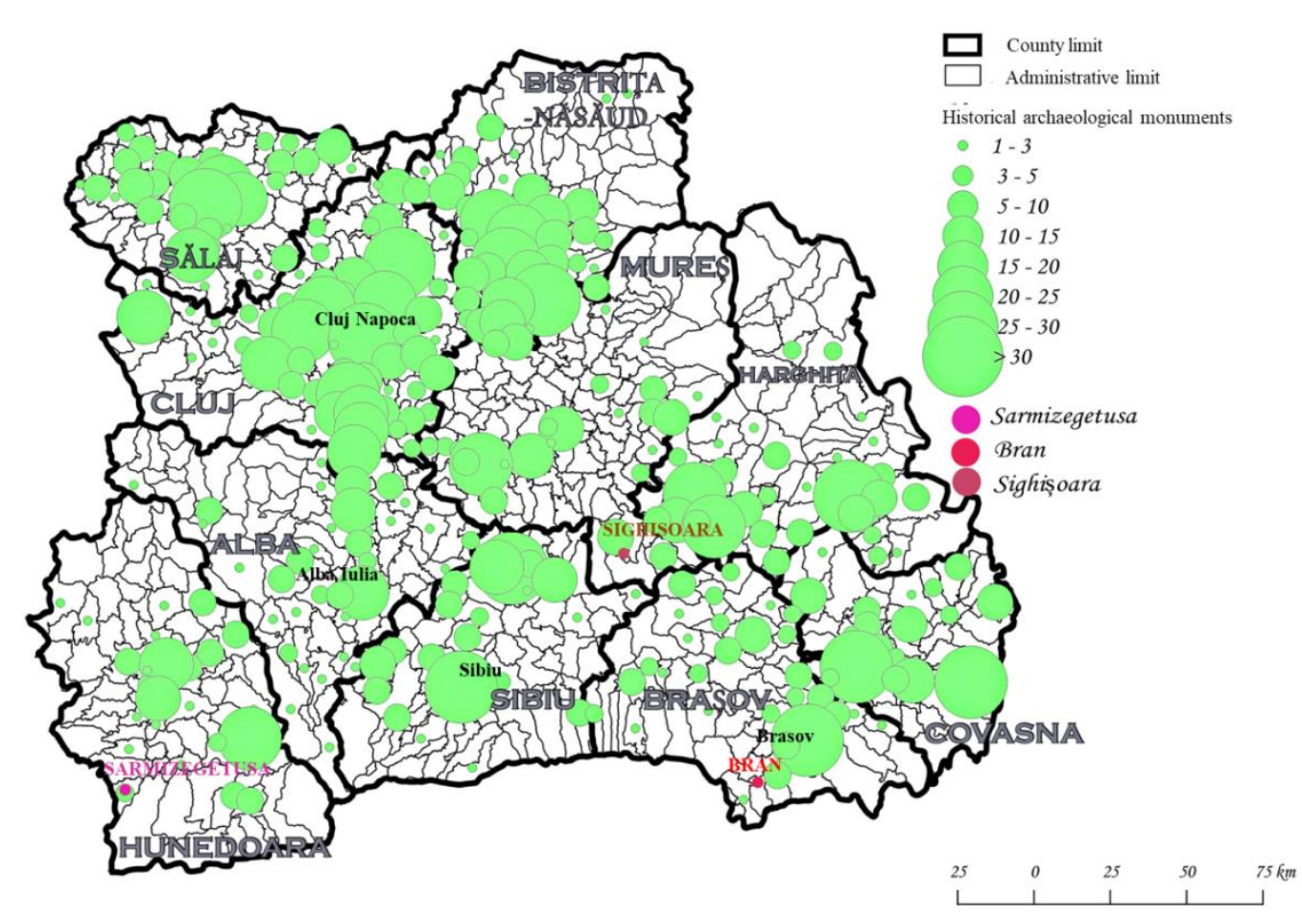

Figure 2. The location of the historical cultural monuments according to the Monuments List made by the Ministry of Culture and National Patrimony of Romania

Most of the historical cultural monuments are accessible to major cities in Transylvania, such as Cluj, Alba Iulia, Sibiu, Brasov, Sighisoara, to which there may be added a number of important citadels, such as Sarmisegetusa, Rasnov, Fagaras and many more. 


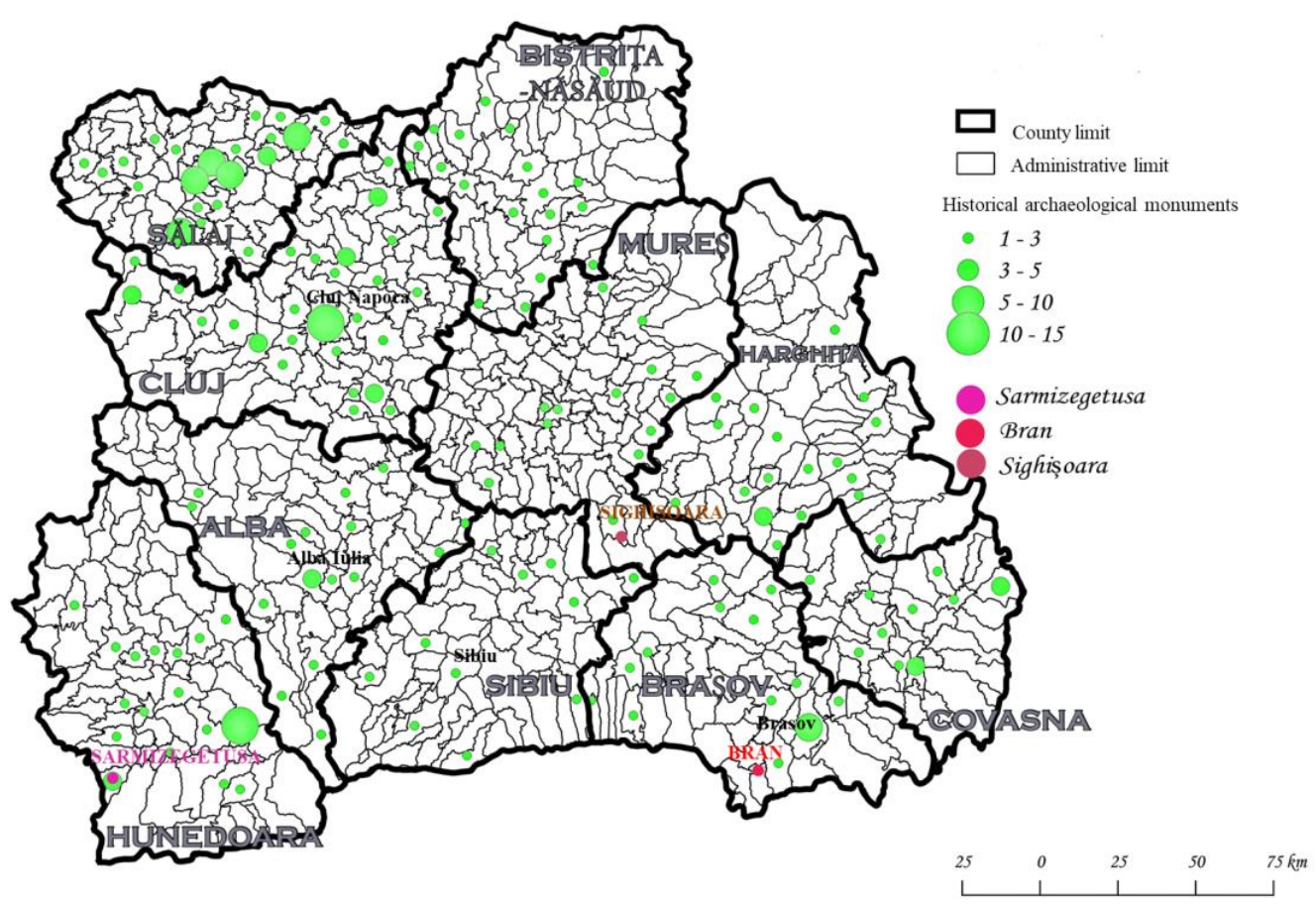

Figure 3. The location of historical cultural monuments that can be cultural tourism objectives according to the field analysis.

The study continues this comparative approach for the category of religious cultural monuments as well, thus making up a graphical representation of the monuments existing in the List of Monuments drawn up by the Ministry of Culture and National Patrimony of Romania (figure 4), and those with easy accessibility from tourist point of view (Figure $5)$.

The buildings of exceptional architectural value, included in the category of historical monuments, preserve the imprint of influences from European art and architecture (figure 6). Their abundance in the list of monuments, as it can be seen in figure six, could create the image of a tourist offer clearly oriented to the south and south-east of the province. Thus, in Sibiu and Brasov counties, these monuments are rendered fairly well. As far as the century they date of, the representative, if not most of the buildings, belong to the eighteenth and nineteenth centuries. Our study, in a more detailed analysis, will refer to these details. The influences in the local, Transylvanian architecture are linked to the European ones, especially those from Central Europe and Western Europe. The same situation is also found in the North-West, Central and Western sides of the region. The same centuries are dominant in architecture, and to these centuries there must be added the twentieth century, by the constructions represented in particular by public institutions. In other words, the admiration of the tourists can be oriented towards the Baroque-style buildings, or they are just for elements of the style caught in an attractive eclectic manner. Secession comes to support the completion of the attractive vision in the urban landscape, while the Neoromanesc, the German neoclassic and the rural architecture specific to the Hungarian people, with the frontons of the houses where the Baroque may be observed, provide the complete picture of the Transylvanian countryside. 


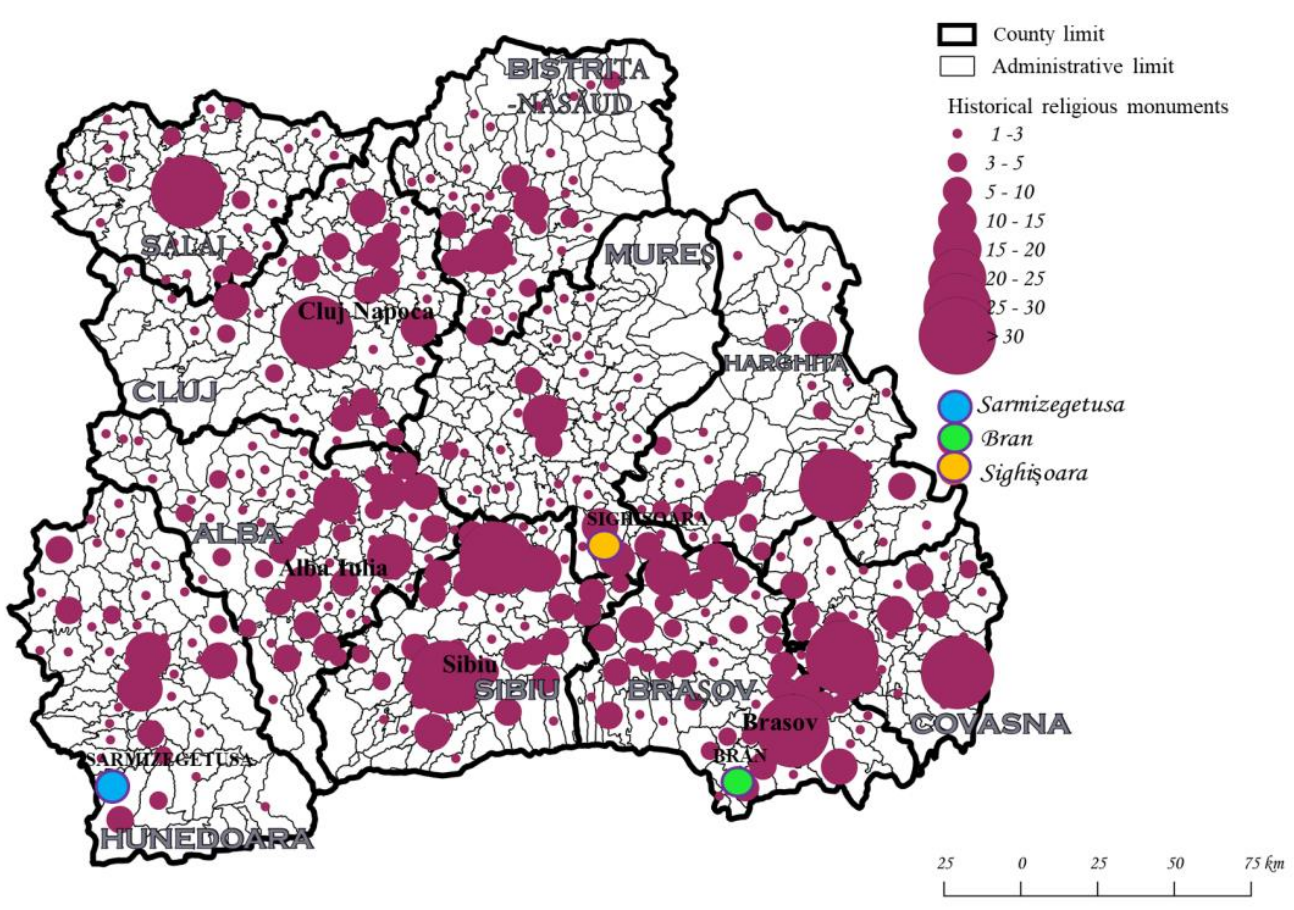

Figure 4. The location of the religious cultural monuments according to the Monument List made by the Ministry of Culture and National Patrimony of Romania

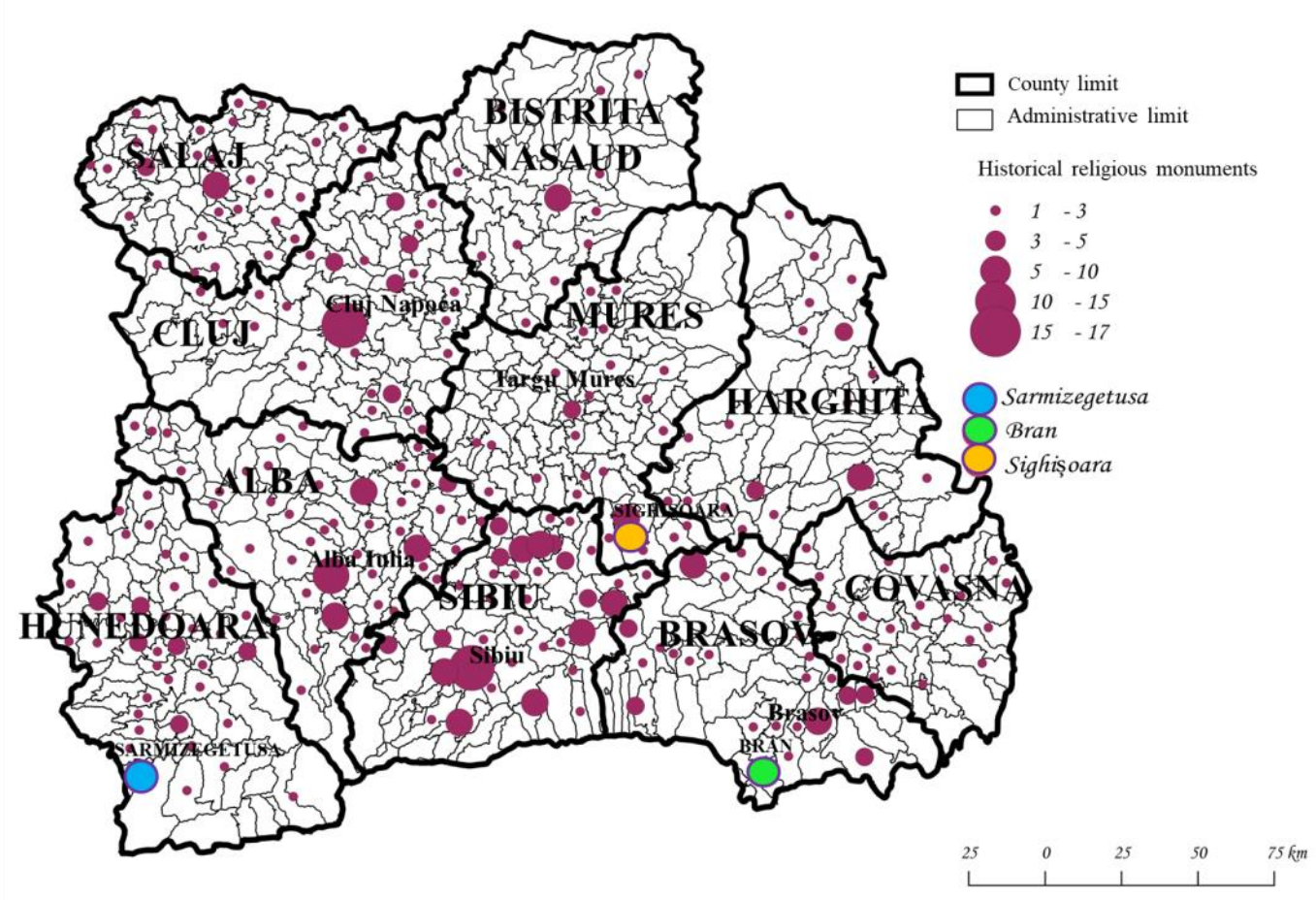

Figure 5. The location of religious cultural monuments that can be cultural and tourist objectives according to the field analysis 


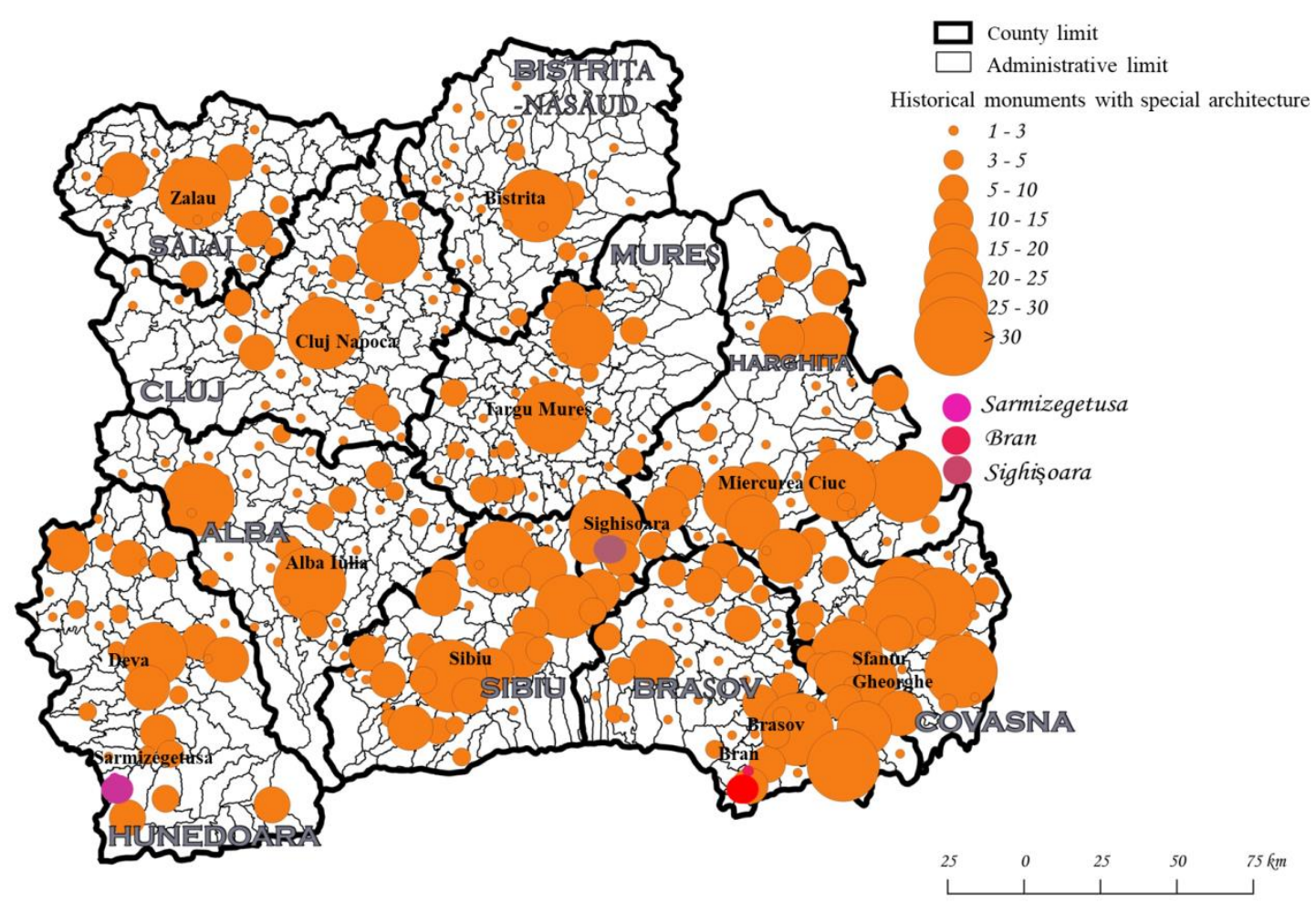

Figure 6. The location of the architectural cultural monuments according to the Monuments List made by the Ministry of Culture and National Patrimony of Romania

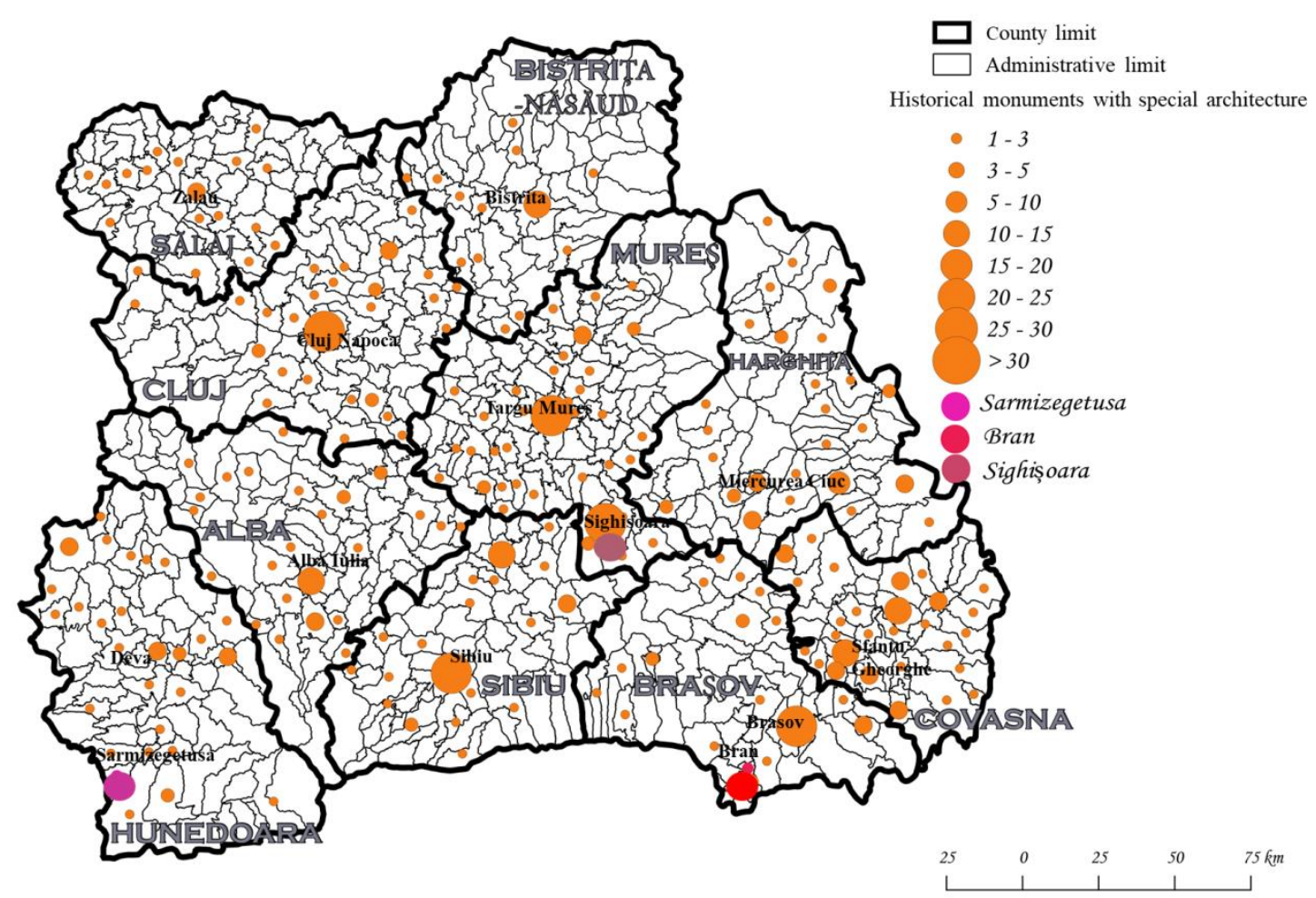

Figure 7. The location of architectural cultural monuments that can be cultural and tourist objectives according to the field analysis 
Gothic architecture, which belongs to a century before the ones mentioned, is present only in places of worship, especially evangelical ones and, less Catholic, these are tributaries to the Baroque and the Romanesque.

Following the field study, there remain as areas covered with architectural monuments that can serve as touristic sights, the south-eastern area, having in the spotlight the city of Brasov, the southern part of the province where the city of Sibiu is representative, the centre of the region where most monuments worth visiting are in the cities of Alba Iulia and Targu Mures, joining the northwest of the province where the city of Cluj offers the complete picture of the architectural styles and of the complete cultural landscape (figure 7).

The results obtained can contribute to the structural modeling of the development of local economies that hold this type of resources and can contribute to the development of methodologies to overcome the restrictions for sustainable development [12], [13], [14], [15].

\section{CONCLUSIONS}

The study highlights the opportunities in terms of the involvement of historical monuments in cultural and tourist activity. Field analyses will contribute to making sustainable tourism offers, as well as to an economically healthy approach. Tourist activity needs to rely on certainties regarding the needs of the tourism consumers. The existence of historical monuments in a geographic area is necessary, but not enough. It is necessary, according to established criteria, to achieve those monuments that can be included in tourist circuits, which can also create cultural touristic circuits and can contribute to the knowledge of the history of an area, in this case of Transylvania, province of Romania.

But there are also restrictive or limiting factors in capitalizing these historical monuments. Some are given the difficult access, or the form of ownership. Buildings or houses with an outstanding architecture, no matter if they are monuments or not, do not always constitute tourist destinations.

Transylvania owns this category of monuments, as well as some monuments belonging to a religious cult.

In support of those interested in cultural tourism and the cultural values expressed by the historical monuments of Transylvania, Romania, the study contributes to the accomplishments of the differences between historical monuments and those historical monuments that can constitute tourist attractions.

\section{REFERENCES}

[1] Barrera-Fernandez Daniel \& Hernandez-Escampa Marco. The impact of urban policy in the management of the tourist-historic city: a comparative study, Pasos - Revista de Turismo y Patrimonio Cultural, vol. 14 / issue 3, pp 705-724, 2016.

[2] Costa Hilário Ana Catarina \& Marreiro das Chagas Márcio. Influencia del escultismo en la formación personal y social de los scouts por medio de la práctica del turismo ecológico y pedagógico, Estudios y perspectivas en turismo, vol. 23 / issue 3, pp 484-50, 2014.

[3] Herman Grigore Vasile \& Varnav Remus. Design elements for promoting attraction case study: Tara Oasului museum (Satu Mare County), Geojournal of tourism and geosites, Oradea, Romania, vol. 14 / issue 2, pp 168-177, 2014. 
[4] Hocaoglu Dilek Ayyildiz. The Role of Design in Cultural Heritage Based City Branding of Beypazari, Milli Folklor, vol. 109, pp 217-232, 2016.

[5] Ilies Dorina Camelia, Baias Stefan, Buhas Raluca, Ilies Alexandru, Herman Grigore Vasile, Gaceu Ovidiu, Dumbrava Razvan \& Maduta Florin Miron. Environmental education in protected areas. Case study from Bihor county, Romania, Geojournal of tourism and geosites, vol. 19/ issue 1, pp 126-132, 2017.

[6] Peptenatu Daniel, Draghici Cristian Constantin \& Merciu Cristina. Characteristics of entrepreneurial profile in some emergent territorial structures in Romania, Actual Problems of Economics, vol. 138, pp 448-458, 2012.

[7] Pintilii Radu Daniel, Peptenatu Daniel, Drăghici Cristian Constantin, Saghin Irina \& Stoian Daniela. Structural Changes in the entrepreneurial profile of the creative industries in Romania. In: Procedia Economics and Finance, vol. 23, pp. 1147-1151, 2014.

[8] Pintilii Radu-Daniel, Daniel Peptenatu, Ana-Maria Ciobotaru, Sorin George Toma, Ana Maria Grigore, Cristian-Constantin Drăghici, Răzvan-Cătălin Dobrea, Adrian Gabriel Simion, Ion Andronache, Camelia Teodorescu \& Daniel Constantin Diaconu. Creative economies in Romania-spatial projections and trends, Bulletin of Geography. Socio-economic Series, Poland, vol. 37, pp 95-108, 2017.

[9] Teodorescu Camelia. Turism cultural, Ed. Transversal, București, România, 2009, pp 5-320.

[10] Teodorescu Camelia \& Porojan Mihaela. Cultural peculiarities - source of incame in toursm, Quality, suppl. Acces to success, Romania, vol. 14, pp 222-225, 2013.

[11] Teodorescu Camelia, Vanturache Radu, Teodorescu Octavian \& Diaconu Daniel Constantin. Proposal for functional conversion - Bucharest Faur, Urbanism. Arhitectura. Constructii, Romania, vol. 7, pp 137-146, 2016.

[12] Draghici Cristian Constantin, Peptenatu Daniel, Simion Adrian Gabriel, Pintilii Radu Daniel, Diaconu Daniel Constantin, Teodorescu Camelia, Papuc Razvan, Grigore Ana Maria \& Dobrea Catalin Razvan. Assessing economic pressure on the forest fund of Maramureș County-Romania, Journal of Forest Science, vol. 62, pp 175-185, 2016.

[13] Peptenatu Daniel, Draghici Cristian Constantin, Stoian Daniela, Pintilii Radu Daniel, Cercleux Andreea Loreta, Merciu Cristina \& Schvab Andrei. Qualitative changes in the entrepreneurial sector in emerging territorial systems - Craiova case study, Acta Geographica Slovenica-Geografski Zbornik, vol. 54, pp 293-304, 2014.

[14] Draghici Cristian Constantin, Andronache Ion, Ahammer Helmut, Peptenatu Daniel, Pintilii Radu Daniel, Ciobotaru Ana Maria, Simion Adrian Gabriel, Dobrea Razvan Catalin, Diaconu Daniel Constantin, Visan Mircea Cristian \& Papuc Razvan Mihail. Spatial evolution of forest areas in the Northern Carpathian Mountains of Romania, Acta Montanistica Slovaca, vol. 22, pp 95-106, 2017. 